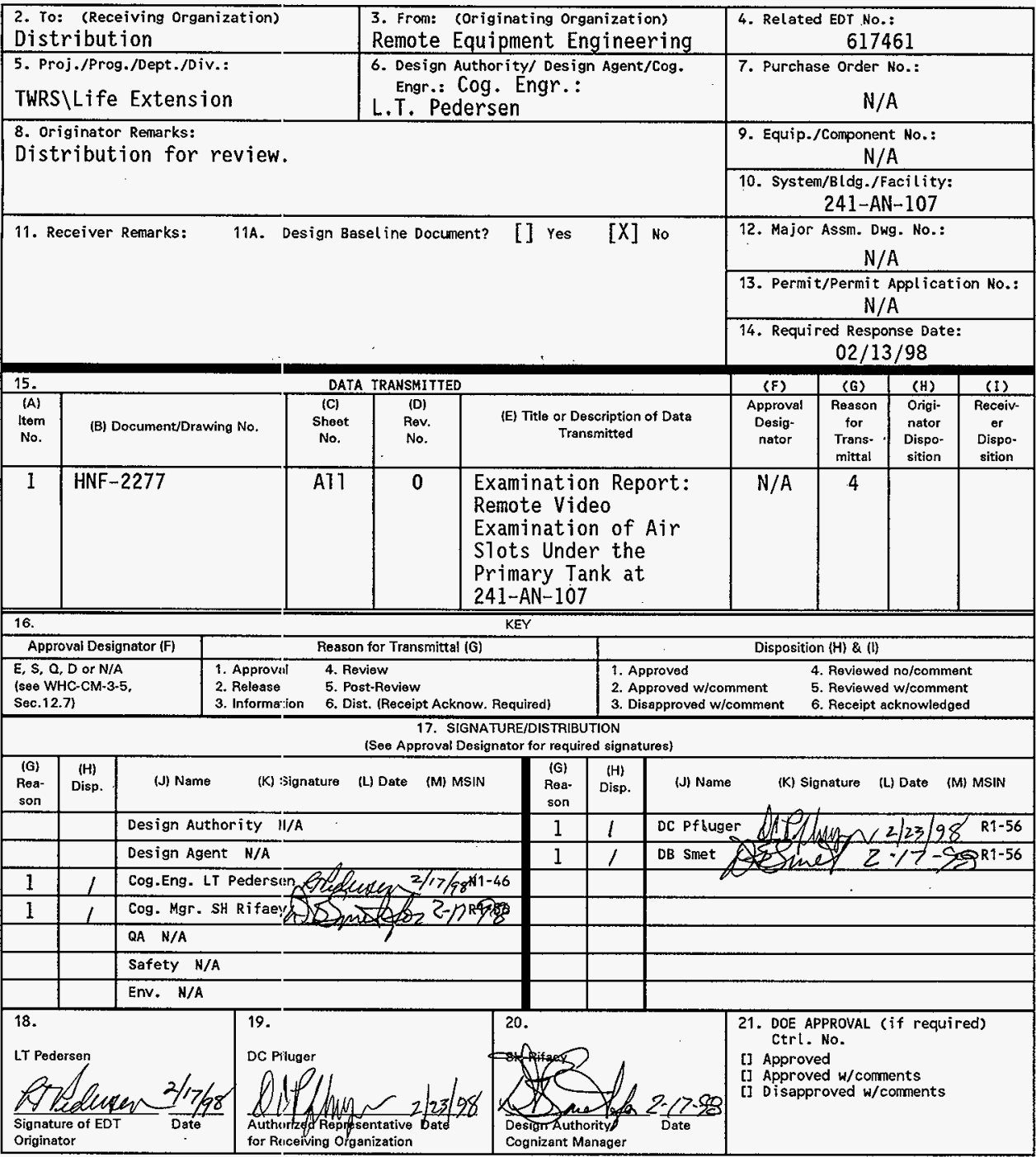




\title{
Examination Report: Remote Video Examination of Air Slots Under the Primary Tank at 241-AN-107
}

\author{
L.T. Pederse'n
}

Lockheed Martin Hanford Company, Richland, WA 99352

U.S. Department of Energy Contract DE-AC06-96RL13200

$\begin{array}{llll}\text { EDT/ECN: } & \text { EDT-617462 } & \text { UC: } 2030 & \\ \text { Org Code: } & 74720 & \text { Charge Code: } & \text { D6329 } \\ \text { B\&R Code: } & \text { EN3130010 } & \text { Tota7 Pages: } 9\end{array}$

Key Words: Examination Report, Air Slot Video Examination, Tank 241-AN-107

Abstract: This examination report documents the results of the remote video examination of air slots in the insulating concrete slab beneath the primary tank at 241-AN-107.

TRADEMARK DISCLAIMER. Reference herein to any specific commercial product, process, or service by trade name, trademark, manufacturer, or otherwise, does not necessarily constitute or imply its endorsement, reccmmendation, or favoring by the United States Government or any agency thereof or its contractors or subcontractors.

Printed in the Urited States of America. To obtain copies of this document, contact: Document Control Services, P.O. Box 950, Mailstop H6-08, Richland WA 99352, Phone (509) 372-2420; Fax (509) 376-4989.

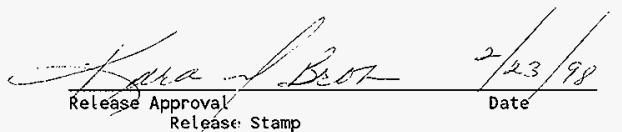

Release: Stamp

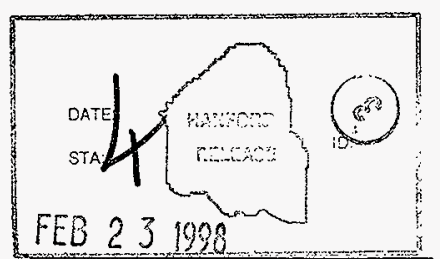


HNF-2277

REV. 0

EXAMINATION REPORT:

RE:MOTE VIDEO EXAMINATION OF AIR SLOTS

UNDER THE PRIMARY TANK AT 241-AN-107

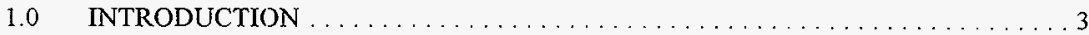

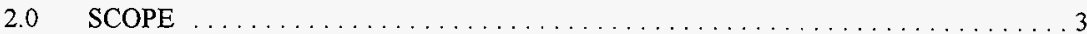

3.0 EQUIPMENT IDESCRIPTION/QUALIFICATION $\ldots \ldots \ldots \ldots \ldots \ldots \ldots \ldots \ldots$

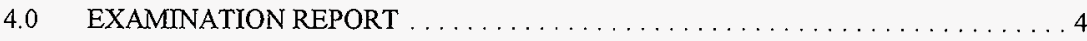

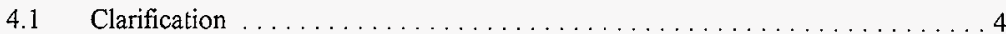

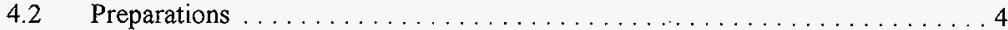

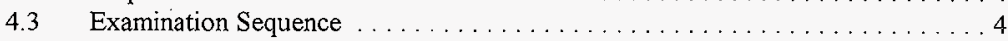

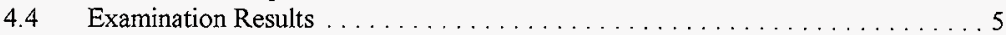

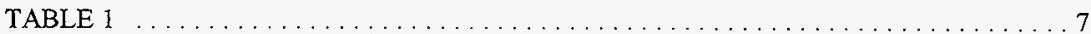

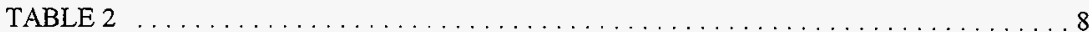

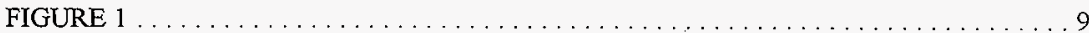




\section{$1.0 \quad$ INTRODUCTION}

This report documents the results of remote video examination of air slots in the insulating concrete slab beneath the primary tank at 241-AN-107.

\section{$2.0 \quad$ SCOPE}

Life Extension Equipment Engineering has selected tank 241-AN-107 for ultrasonic evaluation of tank wall, knuckle, and floor plates. Access to the primary tank floor plates is via the air slots which were formed into the insulating concrete slab during tank construction (reference drawings $\mathrm{H}-2-71105$ and $\mathrm{H}-2-71160$ ). Prior to deployment of the ultrasonic inspection equipment it is desirable to examine the air slots for obstructions and debris which could impede the ultrasonic equipment.

The criteria, equipment description, deliverables, and responsibilities for examination of the air slots are described in HNF-1949, Rev. 0, "Engineering Task Plan for Remote Video Examination of Air Siots Under the '?rimary Tank at 241-AN-107".

\subsection{EQUIPMENT DESCRIPTION/QUALIFICATION}

The remote video equipment utilized for examination of the air slots came almost entirely from existing Remote Equipinent Engineering inventory. The crawler platform used is an Inukton model 380 dual tracked robotic crawler, the video camera is an R.J. Electronics S-VHS format model RCS-2100 camera and control unit, the pan-and-tilt is a Remote Ocean Systems (ROS) model PT-10, and illumination was provided by two Stenning fixtures with General Electric 12 vdc Q35MR11 narrow beam 35 watt spot lamps.

This remote video system was assembled and qualification tested at the Remote Equipment Engineering facility locited in the 400 Area at FMEF. A mockup air slot was constructed from 13 feet of three inch diameter black PVC pipe. One end of the pipe was capped. A qualification card of $18 \%$ neutral gray color containing a $1 / 32$ inch and a $1 / 64$ inch black line was placed inside the cap. The other end of the pipe was covered with a piece of cardboard which had a $2 \frac{1}{2}$ inch square cut in the center to simulate a slot opening. The pipe was set up on blocks to position the centerline $63 / 4$ inches of: the floor.

Qualification testing wes performed informally, and consisted of driving the crawler into position near the simulated slot opening in the mockup pipe, positioning the crawler and camera to view the simulated slot opening, and then adjusting the camera zoom lens and lights to view the qualification card located at the far end of the pipe. Qualification testing was deemed acceptable 
when it was demonstrated that the $1 / 32$ inch black line on the $18 \%$ neutral gray card was discernable with the video system.

\subsection{EXAMINATION REPORT}

\subsection{Clarification}

Riser numbers used in this report have been corrected from those identified in Engineering Task Plan HNF- 1949 to comply with the riser numbering sequence used on drawing $\mathrm{H}$ 14-01050, sheet 7 .

\subsection{Preparations}

Remote video examination of the air slots at tank 241-AN-107 required access to the tank annulus through a 24 inch diameter riser for the crawler, and access through a number of neighboring four inch diameter risers for an overview camera. Twenty-four inch diameter annulus riser AN107-WSTA-RISER-026 was selected for crawler access, and four inch diameter annulus risers AN107-WSTA-RISER-044, -045, -046,-047, -048, and -049 were selected for overview camera access. (See Figure 1).

Risers AN107-WSTA-RISER-026 and -047 still contained the original asbestos bearing gaskets and required asbestos abatement. This was accomplished on Wednesday, January 28, 1998. This work was performed per JCS Package 2E-98-105.

Risers AN107-WSTA-RISER-044 and -048 contained annulus thermocouple trees which were removed on Thursday, January 29, 1998 to allow a clear pathway through the annulus for the crawler. A third annulus thermocouple tree was also removed from riser AN107-WSTA-RISER-040. These three thermocouple trees were installed as part of the Caustic Addition Project in June, 1995. All three thermocouple trees were placed into four inch diameter PVC pipes and stored at AN Farm for possible future use. This work was also performed per JCS Package 2E-98-105.

\subsection{Examination Sequence}

Video examination of air slots in the insulating concrete slab beneath the primary tank at 241-AN-107 conmenced on Friday morning, January 30, 1998. The overview camera was positioned in riser AN107-WSTA-RISER-047 and the crawler was lowered to the annulus floor through riser AN107-WSTA-RISER-026. The crawler was then oriented to proceed in a clockwise direction. The examination proceeded in a clockwise direction around the annulus with the overview camera relocated first to riser AN107-WSTA-RISER-048 and 
HNF-2277

REV. 0

then to riser 107AN-WSTA-RISER-049 in order to keep the crawler in constant view. The annulus leak detector suspended from riser 107AN-WSTA-RISER-061 was raised in order to allow the crawler to pass beneath it. Seventeen air slots were successfully examined. The fnal slot examined is more than 90 degrees radially around the annulus from the point of entry. There was some difficulty in retrieving the crawler from the final location because the crawler cables and retrieval rope had wedged beneath one of the air inlet pipes. After a brief struggle the crawler was freed and retrieved from the annulus. It was decided thar subsequent examinations would not proceed to as great a distance in order to avoid a similar retrieval problem.

On Tuesday, Felruary 3 , the overview camera was positioned in riser AN107-WSTA-RISER-046. The crawler was then lowered to the annulus floor through riser AN107-W\$TA-RISER-026 and positioned to face in the counter-clockwise direction. This time the crawler was driven only about 45 degrees radially around the tank annulus and examined nine air slots. The crawler was then turned around in the annulus and the first nine slots in the clockwise direction were re-examined.

\subsection{Examination Results}

The air slot identification scheme used for this examination designates slot number one as the first slot located in a clockwise direction from the crawler access riser AN107.WSTA-RISER-026. Subsequent slots increment by one in the clockwise direction. Slot number 64 is located immediately below and slightly left of center line of the crawler access riser AN: 07-WSTA-RISER-026. Subsequent slots decrement by one in the counter-clockwise direction. See Figure 1.

Engineering Task Plan HNF-1949 established the goal of examining at least 20 air slots. A total of 26 air slots were successfully examined and video taped. However, not all 26 air slots were examined for the full 13.3 feet length. Ten of the examined air slots, numbers 1 , $3,7,11,15,16,17,64,63$, and 59 , contain one or two thermocouple wires which run the length of the affizcted slots. These thermocouple wires are cut off near the slot openings. These wires reflect a significant amount of light from the camera lamps which produces glare. In order to view the slots for their full length it is necessary to overdrive the lamps to approximately $14 \mathrm{vdc}$ and fully open the iris on the camera lens. Those slots containing thermocouple wires are viewable for only about six to eight feet. Beyond that distance there is too much glare for adequate viewing.

Also, two of the examined slots, numbers 4 and 60 , are located behind the horizontal portions of four inch diameter air inlet pipes. The air inlet pipes blocked most light from 
HNF-2277

REV. 0

the lower lamp naking it impossible to view these two slots for the full length. Only about the first six to eight feet of these slots was examined.

One air slot, number 58, exhibits what appears to be a small metallic object attached to the tank bottom approximately eight to ten feet from the slot entrance. This is possibly a piece of mill scale flaking off of the plate. Slot number 58 is clear, other than this artifact.

The general condition of all 26 air slots examined is very good. The concrete which forms the sides and bottom of each slot is in excellent condition. There is no evidence of spalling or degradation. No construction debris was observed in any of the examined slots.

See Table 1 for a listing of air slots examined and comments. The thirteen slots listed as "clear air slot", with no other comments, contain no obstructions which might hinder the ultrasonic exam:nation of the primary tank bottom plates for the full length of those slots. Slots number 4 and 60 could only be examined for approximately six to eight feet, and may be unsuitable for ultrasonic examination in any case due to their location behind air inlet piping. Slo: number 58 contains an artifact which could impede ultrasonic examination in that slot beyond approximately eight to ten feet. Slot number 12 is located behind an air inlet pipe and was not examined.

Five S-VHS format video tapes were produced during this air slot examination. The master tapes have been cataloged and will be retained and stored in the Remote Equipment Engineering video tape library. Details about these video tapes are listed in Table 2.

The air slot exarnination was completed on Tuesday, February 3, 1998. The air slot examination was performed per JCS Package 2E-97-809. 
TABLE 1

\begin{tabular}{|c|c|}
\hline S16rininuer. & Conuments \\
\hline Slot \#1 & Air slot contains a thermocouple wire \\
\hline Slot \#2 & Clear air slot \\
\hline Slot \#3 & Air slot contains thermocouple wires \\
\hline Slot \#4 & Clear air slot 6-8 feet. Air slot behind air inlet pipe. \\
\hline Slot \#5 & Clee,r air slot \\
\hline Slot \#6 & Clez,r air slot \\
\hline Slot \#7 & Air sot contains thermocouple wires \\
\hline Slot \#8 & Clez,r air slot \\
\hline Slot \#9 & Clezr air slot \\
\hline Slot \#10 & Clear air slot \\
\hline Slot \#11 & Air sot contains thermocouple wires \\
\hline Slot \#12 & Air slot not examined. Air slot behind air inlet pipe. \\
\hline Slot \#13 & Clear air slot \\
\hline Slot \#14 & Clear air slot \\
\hline Slot \#15 & Air slot contains thermocouple wires \\
\hline Slot \#16 & Air : sot contains a thermocouple wire \\
\hline Slot \#17 & Air : lot contains a thermocouple wire \\
\hline Slot \#18 & Clear air slot \\
\hline Slot \#64 & Air slot contains a thermocouple wire \\
\hline Slot \#63 & Air slot contains a thermocouple wire \\
\hline Slot \#62 & Clear air slot \\
\hline Slot \#61 & Clear air slot \\
\hline Slot \#60 & Clear air slot 6-8 feet. Air slot behind air inlet pipe. \\
\hline Slot \#59 & Air slot contains thermocouple wires \\
\hline Slot \#58 & Air slot has artifact attached to tank bottom plate 8-10 feet into slot \\
\hline Slot \#57 & Clear air slot \\
\hline Slot \#56 & Clear air slot \\
\hline
\end{tabular}


TABLE 2

\begin{tabular}{|c|c|c|}
\hline 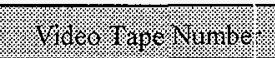 & Date Prodiverd: & Desertition: : \\
\hline 1535 & $01 / 29 / 98$ & $\begin{array}{l}\text { Overview camera footage taken during the } \\
\text { removal of three annulus thermocouple trees } \\
\text { at AN-107 }\end{array}$ \\
\hline 1536 & $01 / 30 / 98$ & $\begin{array}{l}\text { Overview camera footage taken during } \\
\text { crawler deployment in the clockwise direction } \\
\text { at AN-107 annulus }\end{array}$ \\
\hline 1537 & $02 / 03 / 98$ & $\begin{array}{l}\text { Overview camera footage taken during } \\
\text { crawler deployment in the counter-clockwise } \\
\text { direction and in the clockwise direction at } \\
\text { AN-107 annulus }\end{array}$ \\
\hline 1538 & $01 / 30 / 98$ & $\begin{array}{l}\text { Crawler camera footage taken during crawler } \\
\text { deployment in the clockwise direction at } \\
\text { AN-107 annulus }\end{array}$ \\
\hline 1539 & $02 / 03 / 98$ & $\begin{array}{l}\text { Crawler camera footage taken during crawler } \\
\text { deployment in the counter-clockwise direction } \\
\text { and in the clockwise direction at AN-107 } \\
\text { annulus }\end{array}$ \\
\hline
\end{tabular}




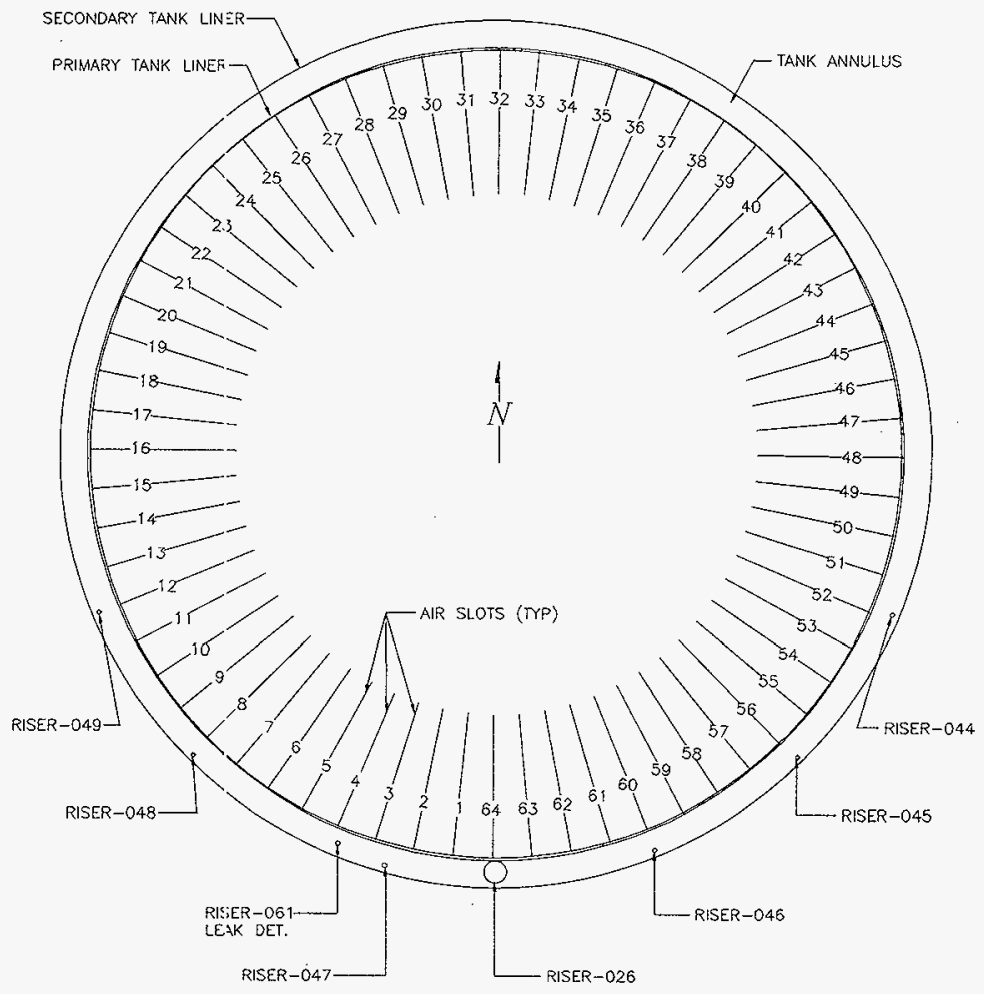

TANK AN-107

FIGURE 1 


\section{DISTRIBUTION SHEET}

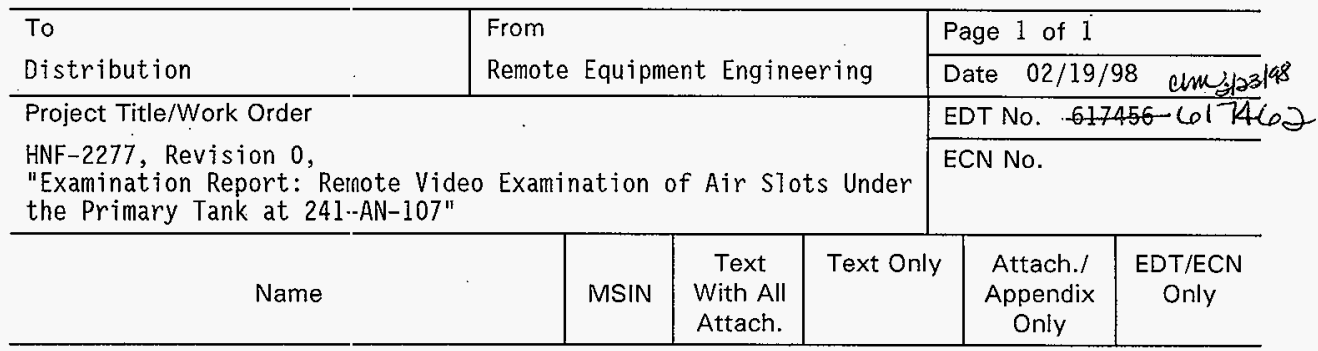

K.G. Carothers

G.A. Leshikar

R.S. Nicholson

L.T. Pedersen

D.C. Pfluger

G.J. Posakony

W.J. Powe 11

M.L. Ramsay

D.B. Smet
R2-1I 1

S0-08 1

S5-05 1

N1-46 1

R1-56 1

K5-26 $\quad 1$

S5-13 1

S7-54 1

R1-56 1 